\title{
Sex, Drugs, and Impulse Regulation: A Perspective on Reducing Transmission Risk Behavior and Improving Mental Health Among MSM Living With HIV
}

\author{
Rachel M. Arends ${ }^{1,2,3 *}$, Thom J. van den Heuvel ${ }^{1,4}$, Eline G. J. Foeken-Verwoert ${ }^{5}$, \\ Karin J. T. Grintjes ${ }^{6}$, Hans J. G. Keizer ${ }^{3}$, Aart H. Schene ${ }^{1,2}$, André J. A. M. van der Ven ${ }^{6}$ \\ and Arnt F. A. Schellekens ${ }^{1,2,7}$ \\ ${ }^{1}$ Department of Psychiatry, Radboud University Medical Center, Nijmegen, Netherlands, ${ }^{2}$ Donders Center for Medical \\ Neuroscience, Donders Institute for Brain, Cognition and Behavior, Nijmegen, Netherlands, ${ }^{3}$ Tactus Addiction Care, \\ Deventer, Netherlands, ${ }^{4}$ Scelta, GGNet, Nijmegen, Netherlands, ${ }^{5}$ Youz, Parnassia Group, Arnhem, Netherlands, \\ ${ }^{6}$ Department of Internal Medicine, Radboud University Medical Center, Nijmegen, Netherlands, ${ }^{7}$ Nijmegen Institute \\ for Scientist-Practitioners in Addiction, Nijmegen, Netherlands
}

OPEN ACCESS

Edited by:

Xiao Zhou,

Zhejiang University, China

Reviewed by:

Wenchao Wang

Beijing Normal University, China Hongfei Yang,

Zhejiang University, China

*Correspondence: Rachel M. Arends Rachel.arends@radboudumc.nl

Specialty section:

This article was submitted to Psychology for Clinical Settings, a section of the journal

Frontiers in Psychology

Received: 04 January 2020 Accepted: 22 April 2020 Published: 28 May 2020

Citation:

Arends RM, van den Heuvel TJ, Foeken-Verwoert EGJ, Grintjes KJT, Keizer HJG, Schene AH, van der Ven AJAM and Schellekens AFA (2020) Sex, Drugs, and Impulse Regulation:

A Perspective on Reducing Transmission Risk Behavior and Improving Mental Health Among MSM Living With HIV. Front. Psychol. 11:1005. doi: 10.3389/fpsyg.2020.01005
Unprotected sexual contact continues to be a main cause of HIV transmission and poses certain key populations at increased risk for HIV infection. One of the populations at high risk are men who have sex with men. A subset of MSM engages in chemsex, whereby consumption of illicit drugs is used to facilitate or enhance sexual activity. This practice can have several negative consequences, such as sexually transmitted infections (including HIV) and mental health problems (including compulsive sexual behavior, addiction, and mood disorders). In this article, we provide our perspective on the current situation that medical professionals dealing with MSM living with HIV often feel empty-handed in how to deal with these behavioral and psychological issues. Close collaboration between somatic and mental health professionals is key to address treatment needs of people living with HIV, regarding the negative consequences of chemsex and their overall quality of life. In this article, we discuss possibilities for psychological treatment, including behavioral skills training to improve impulse control and reduce compulsive sexual behaviors among MSM living with HIV who persistently engage in sexual transmission risk behavior, based on our experience with implementing such an intervention. Important barriers and facilitators for further implementation of behavioral interventions will be discussed. Reduction of HIV transmission risk behavior is needed to achieve the WHO aim to end HIV as a public health threat by 2030. We propose that close collaboration between somatic and mental health professionals and implementation of behavioral interventions for risk populations are key to achieve this goal.

Keywords: chemsex, HIV, intervention, mental health, MSM, risk behavior

Abbreviations: AIDS, acquired immunodeficiency disease; cART, combination antiretroviral treatment; CSB, compulsive sexual behavior; GHB, gamma-hydroxybutyrate; HIV, human immunodeficiency virus; MSM, men who have sex with men; STI(s), sexually transmitted infection(s); WHO, World Health Organization. 


\section{PERSISTENT HIV TRANSMISSION RISK BEHAVIOR AMONG MSM}

HIV remains an important global public health issue (Malekinejad et al., 2008), infecting around 1.8 million people every year (UNAIDS, 2018a). The World Health Organization (WHO) aims to end HIV/AIDS as a public health threat by 2030, as one of the sustainable development goals (WHO, 2016; Bekker et al., 2018). With the increasing availability of combination antiretroviral therapy (cART), HIV infection has transformed into a manageable chronic disease in many parts of the world (Cohen et al., 2013; Deeks et al., 2013). Consequently, the numbers of people living with HIV are increasing, including the physical and emotional challenges of living with HIV (Crepaz et al., 2008; Mutumba and Harper, 2015).

Around 57\% of all new HIV infections in Western societies occur among men who have sex with men (MSM), making them a major risk population (UNAIDS, 2018b). MSM have a 28 times higher risk of contracting HIV, compared to the general population (UNAIDS, 2018b). This is mainly driven by sexual transmission risk behavior, sometimes combined with substance use, in a subpopulation of MSM (Benotsch et al., 1999; Purcell et al., 2001; Pufall et al., 2018). While cART has significantly reduced HIV transmission, access to cART also caused an increase in unsafe sexual practices since the mid-90s. This contributed to an annually increasing rate of sexually transmitted infections (STIs) among MSM, including syphilis, gonorrhea, hepatitis, and chlamydia (Workowski and Bolan, 2015; UNAIDS, 2016). This development also stirred antibiotic resistance in some of these infections and is accompanied by high costs for treatment of e.g., hepatitis C (Nelson, 2003; Crowther-Gibson et al., 2011; Unemo and Shafer, 2011).

Various studies show that around $40 \%$ of MSM living with HIV report persisting sexual transmission risk behavior (Benotsch et al., 1999; Hospers et al., 2005; Van Kesteren et al., 2007; Crepaz et al., 2009), with recent unprotected sexual practices being reported by $39-66 \%$ of seropositive MSM (Benotsch et al., 1999). Furthermore, there is a growing trend for MSM to participate in group sex under the influence of psychoactive drugs, most commonly known as "chemsex" or "party and play" (Evers et al., 2020). Frequently used drugs to increase sexual experiences include crystal methamphetamine (when it is injected called "slamming"), mephedrone and gammahydroxybutyrate (GHB) (Stuart, 2013; Moncrieff and Friend, 2014; McCall et al., 2015; Schmidt et al., 2016; GonzálezBaeza et al., 2018; Pufall et al., 2018). Chemsex increases the risk of transmission of HIV and other STIs (Purcell et al., 2001; Hegazi et al., 2017; Sewell et al., 2017; Pufall et al., 2018). Recent studies from the UK and the Netherlands showed that around $30-40 \%$ of MSM report to have had sex in the context of substance use (Pufall et al., 2018; Evers et al., 2020). Evers et al. (2020) also observed that of the MSM engaging in chemsex, $23 \%$ reported a need for professional counseling, mainly MSM who engaged in chemsex more often, and the most reported subject to discuss was increasing self-control (reported by $52 \%$ ).
In about $14-22 \%$ of MSM living with HIV, ongoing transmission risk behavior develops into compulsive sexual behavior (CSB) (Benotsch et al., 1999; Parsons et al., 2017; Brown et al., 2018). CSB is characterized by a preoccupation with one's sexual desires and an inability to control them, often resulting in more frequent and unsafe sexual encounters (Benotsch et al., 1999; Dew and Chaney, 2005). For people with CSB, having sex can become an alternative strategy to cope with negative emotions such as loneliness, anxiety, stress (Collins et al., 2006; Torres and Gore-Felton, 2007), low self-esteem (Benotsch et al., 1999; Dew and Chaney, 2005), or traumatic stress (Goodman and Fallot, 1998; Stevens et al., 2003). Among MSM living with HIV, CSB is of particular relevance, since it can further contribute to the transmission of STIs, including HIV (Benotsch et al., 1999).

Finally, other mental health issues have also been associated with persisting transmission risk behavior among MSM living with HIV (Crepaz and Marks, 2002; Prince et al., 2007; Bonar et al., 2018). Approximately half of the people living with HIV are diagnosed with a psychiatric disorder during their lives (Crepaz et al., 2008). Most common psychiatric conditions among MSM living with HIV are depression (14-48\% compared with $6-37 \%$ in the general population), anxiety disorders $(16-40 \%$ compared to 6-18\%), and substance use disorders (7-65\% compared to 4-11\%) (Dew et al., 1997; ESEMeD/MHEDEA, 2004; Baumeister and Härter, 2007; Crepaz et al., 2008; Myer et al., 2008). Mental health issues contribute to a lower quality of life (Sherbourne et al., 2000; Berg et al., 2004), and decreased adherence to cART in this population (Pence et al., 2007). Where mental health services often lack expertise regarding HIV, cART, and HIV-specific mental health aspects, somatic healthcare professionals often feel empty-handed when it comes to mental health and addiction issues in their patients (Soto et al., 2004; Cournos et al., 2005; Moncrieff and Friend, 2014; McCall et al., 2015).

In this paper, we provide our perspective on a closer collaboration between somatic and behavioral health professionals, which could enhance the quality of care, improve the mental health and self-control of patients, and decrease societal public health issues regarding this population (Soto et al., 2004; Cargill and Stone, 2005; Moncrieff and Friend, 2014).

\section{BEHAVIORAL INTERVENTION: IDEAS AND EXPERIENCES}

Various studies stress the importance of behavioral interventions in order to reduce transmission risk behavior among MSM (Johnson et al., 2008; Berg, 2009; Higa et al., 2013; Krishnaratne et al., 2016; Brown et al., 2019). Studies show that behavioral interventions that focus on emotion and impulse regulation can increase quality of life, and reduce transmission risk behavior among key populations, including MSM living with HIV (Johnson et al., 2008; Farmer and Golden, 2009; Neacsiu et al., 2014). In addition, previous studies have shown associations between impulsiveness and transmission risk behavior in various key-populations (Horvath and Zuckerman, 1993; Semple et al., 2006; JemmottIII, Jemmott et al., 2015; Danko et al., 2016; 
Arends et al., 2019). Therefore, we postulate that interventions aiming to reduce transmission risk behavior should also target elements as impulse regulation skills. Group therapy might be a preferable option for such interventions, as it helps individuals feel less isolated and ashamed (Schreiber et al., 2011). However, current evidence is also limited, mainly due to methodological limitations, including small sample sizes and observational designs (Johnson et al., 2008). Furthermore, there is a lack of scientifically tested treatment behavioral intervention protocols for chemsex and sexual compulsivity for MSM living with HIV (Evers et al., 2020; Stevens et al., 2020).

To explore the possibilities for future studies and implementation of a behavioral intervention protocol for MSM living with HIV who show persistent sexual transmission risk behavior, we developed a behavioral intervention combining different treatment elements (based on cognitive and dialectical behavior therapy) previously shown to be effective in improving self-awareness, emotion and impulse regulation, and reducing risky behaviors such as substance use, self-harm or sexual risk behavior (Wagner et al., 2004; Crepaz et al., 2008; Covey et al., 2016; Cristea et al., 2017; Maffei et al., 2018; DeCou et al., 2019; Ben-Porath et al., 2020). To the best of our knowledge, this is the first time a cognitive-dialectical behavior therapy protocol is used, mainly focusing on developing insight in one's dysfunctional/risky behavior and increasing coping skills (related to reduced self-management and lowered impulse and emotion regulation) (Neacsiu et al., 2014) in order to reduce sexual transmission risk behavior among MSM living with HIV.

The exploratory intervention consisted of 10 weekly sessions of $2.5 \mathrm{~h}$ group therapy, guided by two psychologists. The intervention consisted of self-acceptance exercises and practicing self-control skills, and discussing people's diary notes and homework assignments. It contained elements of motivational interviewing, mindfulness-based therapy, self-regulation, and risk management skills training (see Table 1 for a general outline of the intervention program). The intervention aimed to assist patients with increasing insight in their sexual- and substance-related behavior (incl. related problems) and providing ways to learn alternative strategies for coping with problems and negative emotions, instead of using drugs or having sex.

TABLE 1 | Overview of treatment components related to therapeutic factors.

\begin{tabular}{ll}
\hline Session & Subject \\
\hline 1 & Introduction, psycho-education, and start with general skills training \\
2 & Mindfulness, creating awareness of current problems \\
3 & Mindfulness and pros/cons of current behavior \\
4 & Distress tolerance, dealing with mental health issues \\
5 & Distress tolerance, alternative ways of coping with negative affect I/O \\
6 & sex or substance use \\
7 & Emotion regulation and impulse control \\
8 & Emotion regulation and self-esteem \\
9 & Interpersonal effectiveness, set boundaries \\
10 & Interpersonal effectiveness, maintaining and severing relationships \\
& Repeating lessons learned, training evaluation and making aftercare
\end{tabular}

All MSM living with HIV being treated at our referral hospital in the eastern part of The Netherlands $(n \approx 425)$, who had multiple STIs in previous year $(n=70)$, and did not have any acute somatic or mental health issues (exclusion criteria), were offered the possibility to participate in the behavioral intervention by their treating nurse practitioners. Subsequently, men who expressed a wish to change their substance- and/or sexual-related risk behavior were approached and screened for participation by a psychologist. Finally, 12 MSM living with HIV participated in the intervention. On average they were 42 years old (range: 25-54). All participating men reported symptoms of CSB and substance use in the previous month. Furthermore, they reported clinically significant levels of anxiety (41\%), stress (32\%), and/or depression (38\%). In a qualitative evaluation, they all reported increased awareness of their transmission risk behavior and its consequences, and more than half (55\%) also experienced behavioral change after the behavioral intervention. Most participants (82\%) reported that the training provided them with new insights into their sexual behavior related problems. Furthermore, all reported having learned alternative strategies to cope with problems and negative emotions, instead of using drugs or having sex. Finally, more than half of the participants (55\%) reported the impulse and emotion regulation skills to be most helpful for them.

Other relevant themes identified during the intervention were lack of self-confidence, problems in intimate relationships, exposure to traumatic experiences, drug abuse, and a lower perceived quality of life. These topics may be of interest for future studies exploring the effects of a behavioral intervention in this target population. Future studies should thereby not only focus on reducing sexual transmission risk behavior and mental health problems but also include positive outcome measures of personal recovery, well-being and (post-traumatic) growth (Kamen et al., 2016; Willie et al., 2016; Moitra et al., 2020). The main barriers that were encountered during recruitment were related to fear for change, feelings of shame or guilt about one's behavior (Gilliland et al., 2011), stigma and concerns about privacy. In addition, some patients expressed little self-efficacy or insight into their behavior. Previous studies have shown that this impedes helpseeking behavior, behavioral change, and adoption of a healthier lifestyle (Gilliland et al., 2011; Schwarzer, 2014).

\section{UPSCALING TARGETED INTERVENTIONS TO REDUCE TRANSMISSION RISK BEHAVIOR}

People who live with HIV often know the risks of transmission risk behavior, but some continue to engage in risky practices despite known negative consequences (McKirnan et al., 1996; Montano and Kasprzyk, 2015). Thus, only providing knowledge on transmission risk behavior and its potential consequences is unlikely to result in sufficient behavioral change (McKirnan et al., 1996; Smith et al., 2012). Based on our exploratory experience with a behavioral group intervention, and supported by several previous studies, we postulate that behavioral intervention is key to achieve WHO sustainable development goals on HIV. 
Behavioral interventions can contribute to increase insight in one's behavior and facilitate behavioral change among people living with HIV (Herbst et al., 2005; Johnson et al., 2008; Covey et al., 2016). Interventions, such as reported here, can improve impulse and emotion regulation skills and therefore reduce "self-medication" with sex and/or substance use (as part of transmission risk behavior) and advance mental health among people living with HIV (Margolin et al., 2007; Salomon et al., 2009; Arends et al., 2019).

This approach requires interdisciplinary collaboration, in order to address unmet mental health needs in people living with HIV. Through interdisciplinary collaboration HIV healthcare professionals can offer more comprehensive assessment and treatment, and mental health care workers can integrate specific HIV-related aspects into their care routines (Sherer et al., 2002; Soto et al., 2004; Cargill and Stone, 2005; Halkitis et al., 2013; Moncrieff and Friend, 2014; UNFPA, 2015). For instance, mental healthcare workers previously reported a need for improved HIV-related knowledge to expand services for people living with HIV and addiction problems (Montague et al., 2015).

Behavioral interventions targeting transmission risks in specific key populations as described here, could be part of a "micro-elimination" approach to achieve the HIV/AIDS-related WHO sustainable development goals. Micro-elimination concerns the reduction of infections to zero in specific key populations (Lazarus et al., 2018). To achieve this, a people-centered organization of health care is required, where a specific population is offered suitable physical and mental healthcare (Mahajan et al., 2008; Lazarus et al., 2017). Though MSM with mental health issues and persistent transmission risk behavior constitute a relatively small proportion of all people living with HIV, the high likelihood of HIV transmission within this population makes them a priority target for preventive interventions (Bourne et al., 2015).

A major issue regarding psychological support is the motivation for treatment. There are various reasons why MSM living with HIV with persisting transmission risk behavior might not ask for help or not participate in a behavioral intervention. Patients often only seek help for their somatic problems, probably due to stigma and secrecy that surround same-sex behavior, sex-related problems, mental health issues or substance use (McKirnan et al., 1996; McCall et al., 2015; Gama et al., 2017). Previous studies show that issues regarding participating in a behavioral intervention can include anxiety to talk about risk behavior, perceived stigma, feelings of shame, and privacy issues as major barriers to participating in the behavioral skills training (Gilliland et al., 2011; Kamarulzaman and Altice, 2015; Raifman et al., 2017). Certain studies suggest that online approaches (eHealth) can circumvent some of these barriers (AmichaiHamburger et al., 2014; Connaughton and McCabe, 2017) and

\section{REFERENCES}

Amichai-Hamburger, Y., Klomek, A. B., Friedman, D., Zuckerman, O., and ShaniSherman, T. (2014). The future of online therapy. Comput. Hum. Behav. 41, 288-294. doi: 10.1016/j.chb.2014.09.016 can be effective in reducing transmission risk behaviors among key populations (Johnson et al., 2008). These kinds of eHealth approaches might be able to reach patients in need who would otherwise not ask for help (Postel et al., 2008). Future studies should investigate whether the transformation of face-to-face interventions, as described here, into eHealth applications holds promise for reducing HIV transmission (e.g., related to CSB or chemsex) in relevant key-populations. Furthermore, future studies should apply a (quasi) experimental study designs including a control group, in order to examine the effectiveness of such an intervention in reducing sexual transmission risk behavior among MSM living with HIV, and improving personal well-being.

Taken together, persisting transmission risk behavior among MSM living with HIV can have a major impact on their quality of life and is of utmost importance from a public health perspective. Interdisciplinary collaboration to develop and implement a tailored behavioral intervention might help to reduce transmission risk behavior and improve quality of life in these patients (Cournos et al., 2005), and might save costs by preventing transmission of STI's (Herbst et al., 2005; Lin et al., 2016). Future studies should provide further evidence for efficacy, and explore ways to tackle barriers for participation in such interventions, for instance by providing online treatment or integrating somatic and mental health care services. We strongly believe that these kinds of behavioral approaches are needed to reach the WHO sustainable development goal to end the HIV/AIDS epidemic by 2030.

\section{DATA AVAILABILITY STATEMENT}

The datasets generated for this study are available on request to the corresponding author.

\section{ETHICS STATEMENT}

The study that was mentioned in this manuscript involved human participants and was reviewed and approved by the Central Committee on Research Involving Human Subjects region Arnhem-Nijmegen. Furthermore, the participants provided their written informed consent to take part in the study.

\section{AUTHOR CONTRIBUTIONS}

RA wrote the main parts of the manuscript. TH, EF-V, KG, AFS, AHS, and AV gave relevant feedback on the content. AFS provided major feedback and adjustments of text elements. All authors read and approved the final manuscript.

Arends, R. M., Nelwan, E. J., Soediro, R., Van Crevel, R., Alisjahbana, B., Pohan, H. T., et al. (2019). Associations between impulsivity, risk behavior and HIV, HBV, HCV and syphilis seroprevalence among female prisoners in Indonesia: a cross-sectional study. PLoS One 14:e0207970. doi: 10.1371/journal.pone. 0207970 
Baumeister, H., and Härter, M. (2007). Prevalence of mental disorders based on general population surveys. Soc. Psychiatry Psychiatr. Epidemiol. 42, 537-546. doi: 10.1007/s00127-007-0204-1

Bekker, L.-G., Alleyne, G., Baral, S., Cepeda, J., Daskalakis, D., Dowdy, D., et al. (2018). Advancing global health and strengthening the HIV response in the era of the sustainable development goals: the International AIDS Society-Lancet Commission. Lancet 392, 312-358. doi: 10.1016/s0140-6736(18)31070-5

Benotsch, E. G., Kalichman, S. C., and Kelly, J. A. (1999). Sexual compulsivity and substance use in HIV-seropositive men who have sex with men: prevalence and predictors of high-risk behaviors. Addict. Behav. 24, 857-868. doi: 10.1016/ s0306-4603(99)00056-8

Ben-Porath, D., Duthu, F., Luo, T., Gonidakis, F., Compte, E. J., and Wisniewski, L. (2020). Dialectical behavioral therapy: an update and review of the existing treatment models adapted for adults with eating disorders. Eat. Disord. 28, 101-121. doi: 10.1080/10640266.2020.1723371

Berg, M. B., Mimiaga, M. J., and Safren, S. A. (2004). Mental health concerns of HIV-infected gay and bisexual men seeking mental health services: an observational study. AIDS Patient Care STDS. 18, 635-643. doi: 10.1089/apc. 2004.18.635

Berg, R. (2009). The effectiveness of behavioural and psychosocial HIV/STI prevention interventions for MSM in Europe: a systematic review. Eurosurveillance 14:19430.

Bonar, E. E., Walton, M. A., Barry, K. L., Bohnert, A. S., Chermack, S. T., Cunningham, R. M., et al. (2018). Sexual HIV risk behavior outcomes of brief interventions for drug use in an inner-city emergency department: secondary outcomes from a randomized controlled trial. Drug Alcohol Depend. 183, 217-224. doi: 10.1016/j.drugalcdep.2017.10.036

Bourne, A., Reid, D., Hickson, F., Torres-Rueda, S., and Weatherburn, P. (2015). Illicit drug use in sexual settings ('chemsex') and HIV/STI transmission risk behaviour among gay men in South London: findings from a qualitative study. Sex Transm. Infect. 91, 564-568. doi: 10.1136/sextrans-2015-052052

Brown, J. L., Vanable, P. A., Bostwick, R. A., and Carey, M. P. (2019). A pilot intervention trial to promote sexual health and stress management among HIVinfected men who have sex with men. AIDS Behav. 23, 48-59. doi: 10.1007/ s10461-018-2234-y

Brown, M. J., Serovich, J. M., and Kimberly, J. A. (2018). Vengeance, sexual compulsivity and self-efficacy among men who have sex with men living with HIV. AIDS Care 30, 325-329. doi: 10.1080/09540121.2017.1360994

Cargill, V. A., and Stone, V. E. (2005). HIV/AIDS: a minority health issue. Med. Clin. 89, 895-912. doi: 10.1016/j.mcna.2005.03.005

Cohen, M. S., Smith, M. K., Muessig, K. E., Hallett, T. B., Powers, K. A., and Kashuba, A. D. (2013). Antiretroviral treatment of HIV-1 prevents transmission of HIV-1: where do we go from here? Lancet 382, 1515-1524. doi: 10.1016/ s0140-6736(13)61998-4

Collins, P. Y., Holman, A. R., Freeman, M. C., and Patel, V. (2006). What is the relevance of mental health to HIV/AIDS care and treatment programs in developing countries? A systematic review. AIDS 20, 1571-1582. doi: 10.1097/ 01.aids.0000238402.70379.d4

Connaughton, C., and McCabe, M. (2017). "Internet-based sex therapy," in The Wiley Handbook of Sex Therapy, ed. Z. Peterson (Oxford: John Wiley \& Sons Ltd), 483. doi: 10.1002/9781118510384.ch30

Cournos, F., Mckinnon, K., and Wainberg, M. (2005). What can mental health interventions contribute to the global struggle against HIV/AIDS? World Psychiatry. 4:135.

Covey, J., Rosenthal-Stott, H. E., and Howell, S. J. (2016). A synthesis of metaanalytic evidence of behavioral interventions to reduce HIV/STIs. J. Behav. Med. 39, 371-385. doi: 10.1007/s10865-016-9714-1

Crepaz, N., and Marks, G. (2002). Towards an understanding of sexual risk behavior in people living with HIV: a review of social, psychological, and medical findings. AIDS 16, 135-149. doi: 10.1097/00002030-200201250-00002

Crepaz, N., Marks, G., Liau, A., Mullins, M. M., Aupont, L. W., Marshall, K. J., et al. (2009). Prevalence of unprotected anal intercourse among HIV-diagnosed MSM in the United States: a meta-analysis. AIDS 23, 1617-1629. doi: 10.1097/ qad.0b013e32832effae

Crepaz, N., Passin, W. F., Herbst, J. H., Rama, S. M., Malow, R. M., Purcell, D. W., et al. (2008). Meta-analysis of cognitive-behavioral interventions on HIV-positive persons' mental health and immune functioning. Health Psychol. 27, 4-14. doi: 10.1037/0278-6133.27.1.4
Cristea, I. A., Gentili, C., Cotet, C. D., Palomba, D., Barbui, C., and Cuijpers, P. (2017). Efficacy of psychotherapies for borderline personality disorder: a systematic review and meta-analysis. JAMA psychiatry 74, 319-328.

Crowther-Gibson, P., Govender, N., Lewis, D., Bamford, C., Brink, A., Von Gottberg, A., et al. (2011). Part IV. Human infections and antibiotic resistance. S. Afr. Med. J. 101, 567-578.

Danko, M., Buzwell, S., and Earle, M. (2016). Men at risk of HIV: sexual sensation seeking, sexual compulsivity and sexual risk behavior among australian MSM who frequently present for post-exposure prophylaxis. J. Treat. Prevent. 23, 324-341. doi: 10.1080/10720162.2016.1140605

DeCou, C. R., Comtois, K. A., and Landes, S. J. (2019). Dialectical behavior therapy is effective for the treatment of suicidal behavior: a meta-analysis. Behav. Ther. 50, 60-72. doi: 10.1016/j.beth.2018.03.009

Deeks, S. G., Lewin, S. R., and Havlir, D. V. (2013). The end of AIDS: HIV infection as a chronic disease. Lancet 382, 1525-1533. doi: 10.1016/s0140-6736(13) 61809-7

Dew, B. J., and Chaney, M. P. (2005). The relationship among sexual compulsivity, internalized homophobia, and HIV at-risk sexual behavior in gay and bisexual male users of internet chat rooms. Sex. Addict. Compul. 12, 259-273. doi: $10.1080 / 10720160500362306$

Dew, M., Becker, J., Sanchez, J., Caldararo, R., Lopez, O., Wess, J., et al. (1997). Prevalence and predictors of depressive, anxiety and substance use disorders in HIV-infected and uninfected men: a longitudinal evaluation. Psychol. Med. 27, 395-409. doi: 10.1017/s0033291796004552

ESEMeD/MHEDEA (2004). Prevalence of mental disorders in Europe: results from the European study of the epidemiology of mental disorders (ESEMeD) project. Acta Psychiatr. Scand. 109, 21-27. doi: 10.1111/j.1600-0047.2004.00327.x

Evers, Y., Hoebe, C., Dukers-Muijrers, N., Kampman, C., Kuizenga-Wessel, S., Shilue, D., et al. (2020). Sexual, addiction and mental health care needs among men who have sex with men practicing chemsex-a cross-sectional study in the Netherlands. Prevent. Med. Rep. 18:101074. doi: 10.1016/j.pmedr.2020.101074

Farmer, R. F., and Golden, J. A. (2009). The forms and functions of impulsive actions: implications for behavioral assessment and therapy. Int. J. Behav. Consult. Ther. 5, 12-30. doi: 10.1037/h0100870

Gama, A., Martins, M. O., and Dias, S. (2017). HIV research with men who have sex with men (MSM): advantages and challenges of different methods for most appropriately targeting a key population. AIMS Public Health 4:221. doi: 10.3934/publichealth.2017.3.221

Gilliland, R., South, M., Carpenter, B. N., and Hardy, S. A. (2011). The roles of shame and guilt in hypersexual behavior. Sex. Addict. Compul. 18, 12-29. doi: 10.1080/10720162.2011.551182

González-Baeza, A., Dolengevich-Segal, H., Pérez-Valero, I., Cabello, A., Téllez, M. J., Sanz, J., et al. (2018). Sexualized drug use (Chemsex) is associated with high-risk sexual behaviors and sexually transmitted infections in HIVpositive men who have sex with men: data from the U-SEX GESIDA 9416 study. AIDS Patient Care STDS 32, 112-118. doi: 10.1089/apc.2017. 0263

Goodman, L. A., and Fallot, R. D. (1998). HIV risk-behavior in poor urban women with serious mental disorders: association with childhood physical and sexual abuse. Am. J. Orthopsychiatry 68, 73-83. doi: 10.1037/h0080272

Halkitis, P. N., Wolitski, R. J., and Millett, G. A. (2013). A holistic approach to addressing HIV infection disparities in gay, bisexual, and other men who have sex with men. Am. Psychol. 68:261. doi: 10.1037/a0032746

Hegazi, A., Lee, M., Whittaker, W., Green, S., Simms, R., Cutts, R., et al. (2017). Chemsex and the city: sexualised substance use in gay bisexual and other men who have sex with men attending sexual health clinics. Int. J. STD AIDS 28, 362-366. doi: 10.1177/0956462416651229

Herbst, J. H., Sherba, R. T., Crepaz, N., Deluca, J. B., Zohrabyan, L., Stall, R. D., et al. (2005). A meta-analytic review of HIV behavioral interventions for reducing sexual risk behavior of men who have sex with men. JAIDS 39, 228-241. doi: 10.1521/aeap.2012.24.3.228

Higa, D. H., Crepaz, N., Marshall, K. J., Kay, L., Vosburgh, H. W., Spikes, P., et al. (2013). A systematic review to identify challenges of demonstrating efficacy of HIV behavioral interventions for gay, bisexual, and other men who have sex with men (MSM). AIDS Behav. 17, 1231-1244. doi: 10.1007/s10461-0130418-Z

Horvath, P., and Zuckerman, M. (1993). Sensation seeking, risk appraisal, and risky behavior. Pers. Individ. Differ. 14, 41-52. doi: 10.1016/0191-8869(93)90173-z 
Hospers, H. J., Kok, G., Harterink, P., and De Zwart, O. (2005). A new meeting place: chatting on the Internet, e-dating and sexual risk behaviour among Dutch men who have sex with men. AIDS 19, 1097-1101. doi: 10.1097/01.aids. 0000174457.08992 .62

Jemmott, J. B. III, Jemmott, L. S., O’leary, A., Icard, L. D., Rutledge, S. E., Stevens, R., et al. (2015). On the efficacy and mediation of a one-on-one HIV riskreduction intervention for African American men who have sex with men: a randomized controlled trial. AIDS Behav. 19, 1247-1262. doi: 10.1007/s10461014-0961-2

Johnson, W. D., Diaz, R. M., Flanders, W. D., Goodman, M., Hill, A. N., Holtgrave, D., et al. (2008). Behavioral interventions to reduce risk for sexual transmission of HIV among men who have sex with men. Cochrane Database Syst. Rev. 3:CD001230. doi: 10.1002/14651858.CD001230.pub2

Kamarulzaman, A., and Altice, F. L. (2015). The challenges in managing HIV in people who use drugs. Curr. Opin. Infect. Dis. 28:10. doi: 10.1097/qco. 0000000000000125

Kamen, C., Vorasarun, C., Canning, T., Kienitz, E., Weiss, C., Flores, S., et al. (2016). The impact of stigma and social support on development of posttraumatic growth among persons living with HIV. J. Clin. Psychol. Med. Settings 23, 126-134. doi: 10.1007/s10880-015-9447-2

Krishnaratne, S., Hensen, B., Cordes, J., Enstone, J., and Hargreaves, J. R. (2016). Interventions to strengthen the HIV prevention cascade: a systematic review of reviews. Lancet HIV 3, e307-e317. doi: 10.1016/s2352-3018(16)30038-8

Lazarus, J. V., Safreed-Harmon, K., Thursz, M. R., Dillon, J. F., El-Sayed, M. H., Elsharkawy, A. M., et al. (2018). The micro-elimination approach to eliminating hepatitis C: strategic and operational considerations. Semin. Liver Dis. 38, 181-192. doi: 10.1055/s-0038-1666841

Lazarus, J. V., Wiktor, S., Colombo, M., and Thursz, M. (2017). Micro-eliminationA path to global elimination of hepatitis C. J. Hepatol. 67, 665-666. doi: 10.1016/j.jhep.2017.06.033

Lin, F., Farnham, P. G., Shrestha, R. K., Mermin, J., and Sansom, S. L. (2016). Cost effectiveness of HIV prevention interventions in the US. Am. J. Prevent. Med. 50, 699-708. doi: 10.1016/j.amepre.2016.01.011

Maffei, C., Cavicchioli, M., Movalli, M., Cavallaro, R., and Fossati, A. (2018). Dialectical behavior therapy skills training in alcohol dependence treatment: findings based on an open trial. Subst. Use Misuse 53, 2368-2385. doi: 10.1080/ 10826084.2018.1480035

Mahajan, A. P., Sayles, J. N., Patel, V. A., Remien, R. H., Ortiz, D., Szekeres, G., et al. (2008). Stigma in the HIV/AIDS epidemic: a review of the literature and recommendations for the way forward. AIDS 22, S67. doi: 10.1097/01.aids. 0000327438.13291 .62

Malekinejad, M., Johnston, L. G., Kendall, C., Kerr, L. R. F. S., Rifkin, M. R., and Rutherford, G. W. (2008). Using respondent-driven sampling methodology for HIV biological and behavioral surveillance in international settings: a systematic review. AIDS Behav. 12, 105-130. doi: 10.1007/s10461-008-9421-1

Margolin, A., Schuman-Olivier, Z., Beitel, M., Arnold, R. M., Fulwiler, C. E., and Avants, S. K. (2007). A preliminary study of spiritual self-schema (3-S+) therapy for reducing impulsivity in HIV-positive drug users. J. Clin. Psychol. 63, 979-999. doi: 10.1002/jclp.20407

McCall, H., Adams, N., Mason, D., and Willis, J. (2015). What is chemsex and why does it matter? BMJ 351:h5790. doi: 10.1136/bmj.h5790

McKirnan, D. J., Ostrow, D. G., and Hope, B. (1996). Sex, drugs and escape: a psychological model of HIV-risk sexual behaviours. AIDS Care 8, 655-670. doi: 10.1080/09540129650125371

Moitra, E., Tarantino, N., Garnaat, S. L., Pinkston, M. M., Busch, A. M., Weisberg, R. B., et al. (2020). Using behavioral psychotherapy techniques to address HIV patients' pain, depression, and well-being. Psychotherapy 57:83. doi: 10.1037/ pst0000258

Moncrieff, M., and Friend, L. (2014). Out of Your Mind. London: London Friend.

Montague, B. T., Kahler, C. W., Colby, S. M., Mchugh, R. K., Squires, D., Fitzgerald, B., et al. (2015). Attitudes and training needs of New England HIV care and addiction treatment providers: opportunities for better integration of HIV and alcohol treatment services. Addict. Disord. Their Treat. 14:16. doi: 10.1097/adt. 0000000000000040

Montano, D. E., and Kasprzyk, D. (2015). "Theory of reasoned action, theory of planned behavior, and the integrated behavioral model," in Health Behavior: Theory, Research and Practice, eds K. Glanz, B. K. Rimer, and K. Viswanath (Hoboken, NJ: John Wiley \& Sons), 95-124.
Mutumba, M., and Harper, G. W. (2015). Mental health and support among young key populations: an ecological approach to understanding and intervention. J. Int. AIDS Soc. 18:19429. doi: 10.7448/ias.18.2.19429

Myer, L., Smit, J., Roux, L. L., Parker, S., Stein, D. J., and Seedat, S. (2008). Common mental disorders among HIV-infected individuals in South Africa: prevalence, predictors, and validation of brief psychiatric rating scales. AIDS Patient Care STDS. 22, 147-158. doi: 10.1089/apc.2007.0102

Neacsiu, A. D., Bohus, M., and Linehan, M. M. (2014). "Dialectical behavior therapy: an intervention for emotion dysregulation," in Handbook of Emotion Regulation, ed. J. J. Gross (New York, NY: Guilford Press), 491-508.

Nelson, R. (2003). Antibiotic development pipeline runs dry. Lancet 362, $1726-$ 1727. doi: 10.1016/s0140-6736(03)14885-4

Parsons, J. T., Rendina, H. J., Moody, R. L., Gurung, S., Starks, T. J., and Pachankis, J. E. (2017). Feasibility of an emotion regulation intervention to improve mental health and reduce HIV transmission risk behaviors for HIV-positive gay and bisexual men with sexual compulsivity. AIDS Behav. 21, 1540-1549. doi: 10.1007/s10461-016-1533-4

Pence, B. W., Miller, W. C., Gaynes, B. N., and Eron, J. J. Jr. (2007). Psychiatric illness and virologic response in patients initiating highly active antiretroviral therapy. JAIDS 44, 159-166. doi: 10.1097/qai.0b013e31802c2f51

Postel, M. G., De Haan, H. A., and De Jong, C. A. (2008). E-therapy for mental health problems: a systematic review. Telemed. J. E Health 14, 707-714. doi: 10.1089/tmj.2007.0111

Prince, M., Patel, V., Saxena, S., Maj, M., Maselko, J., Phillips, M. R., et al. (2007). No health without mental health. Lancet 370, 859-877. doi: 10.1089/tmj.2007.0111

Pufall, E., Kall, M., Shahmanesh, M., Nardone, A., Gilson, R., Delpech, V., et al. (2018). Sexualized drug use ('chemsex') and high-risk sexual behaviours in HIV-positive men who have sex with men. HIV Med. 19, 261-270. doi: 10.1111/hiv.12574

Purcell, D. W., Parsons, J. T., Halkitis, P. N., Mizuno, Y., and Woods, W. J. (2001). Substance use and sexual transmission risk behavior of HIV-positive men who have sex with men. J. Subst. Abuse 13, 185-200. doi: 10.1016/s0899-3289(01) 00072-4

Raifman, J. R., Flynn, C., and German, D. (2017). Healthcare provider contact and pre-exposure prophylaxis in Baltimore men who have sex with men. Am. J. Prevent. Med. 52, 55-63. doi: 10.1016/j.amepre.2016.07.031

Salomon, E. A., Mimiaga, M. J., Husnik, M. J., Welles, S. L., Manseau, M. W., Montenegro, A. B., et al. (2009). Depressive symptoms, utilization of mental health care, substance use and sexual risk among young men who have sex with men in EXPLORE: implications for age-specific interventions. AIDS Behav. 13:811. doi: 10.1007/s10461-008-9439-4

Schmidt, A. J., Bourne, A., Weatherburn, P., Reid, D., Marcus, U., Hickson, F., et al. (2016). Illicit drug use among gay and bisexual men in 44 cities: findings from the European MSM Internet Survey (EMIS). Int. J. Drug Policy. 38, 4-12. doi: 10.1016/j.drugpo.2016.09.007

Schreiber, L. R., Odlaug, B. L., and Grant, J. E. (2011). "Compulsive sexual behavior: phenomenology and epidemiology," in The Oxford Handbook of Impulse Control Disorders, ed. P. E. Nathan (Oxford: Oxford University Press), 165.

Schwarzer, R. (2014). Self-Efficacy: Thought Control of Action. New York: Taylor \& Francis Group.

Semple, S. J., Zians, J., Grant, I., and Patterson, T. L. (2006). Methamphetamine use, impulsivity, and sexual risk behavior among HIV-positive men who have sex with men. J. Addict. Dis. 25, 105-114. doi: 10.1300/j069v25n04_10

Sewell, J., Miltz, A., Lampe, F. C., Cambiano, V., Speakman, A., Phillips, A. N., et al. (2017). Poly drug use, chemsex drug use, and associations with sexual risk behaviour in HIV-negative men who have sex with men attending sexual health clinics. Int. J. Drug Policy 43, 33-43. doi: 10.1016/j.drugpo.2017.01.001

Sherbourne, C. D., Hays, R. D., Fleishman, J. A., Vitiello, B., Magruder, K. M., Bing, E. G., et al. (2000). Impact of psychiatric conditions on health-related quality of life in persons with HIV infection. Am. J. Psychiatry 157, 248-254. doi: 10.1176/appi.ajp.157.2.248

Sherer, R., Stieglitz, K., Narra, J., Jasek, J., Green, L., Moore, B., et al. (2002). HIV multidisciplinary teams work: support services improve access to and retention in HIV primary care. AIDS Care 14, 31-44. doi: 10.1080/09540120220149975

Smith, L. R., Fisher, J. D., Cunningham, C. O., and Amico, K. R. (2012). Understanding the behavioral determinants of retention in HIV care: a qualitative evaluation of a situated information, motivation, behavioral skills 
model of care initiation and maintenance. AIDS Patient Care STDS 26, 344-355. doi: 10.1089/apc.2011.0388

Soto, T. A., Bell, J., Pillen, M., Hiv/Aids Treatment Adherence, and Health Outcomes and Cost Study Group (2004). Literature on integrated HIV care: a review. AIDS Care 16, 43-55. doi: 10.1080/09540120412331315295

Stevens, O., Moncrieff, M., and Gafos, M. (2020). Chemsex-related drug use and its association with health outcomes in men who have sex with men: a crosssectional analysis of Antidote clinic service data. Sex. Trans. Infect. 96, 124-130. doi: 10.1136/sextrans-2019-054040

Stevens, S. J., Murphy, B. S., and Mcknight, K. (2003). Traumatic stress and gender differences in relationship to substance abuse, mental health, physical health, and HIV risk behavior in a sample of adolescents enrolled in drug treatment. Child Maltreat. 8, 46-57. doi: 10.1177/1077559502239611

Stuart, D. (2013). Sexualised drug use by MSM: background, current status and response. HIV Nurs. 13, 6-10.

Torres, H. L., and Gore-Felton, C. (2007). Compulsivity, substance use, and loneliness: the loneliness and sexual risk model (LSRM). Sex. Addict. Compul. 14, 63-75. doi: 10.1080/10720160601150147

UNAIDS (2016). Prevention Gap Report. Geneva: Joint United Nations Programme on HIV/AIDS.

UNAIDS (2018a). AIDS Info: Epidemiological Status, People Living with $H I V$. Available online at: www.unaids.org/en/dataanalysis/datatools/aidsinfo/ (accessed April 16, 2019)

UNAIDS (2018b). Miles to Go: Closing Gaps, Breaking Barriers, Righting Injustices. Geneva: UNAIDS.

Unemo, M., and Shafer, W. M. (2011). Antibiotic resistance in Neisseria gonorrhoeae: origin, evolution, and lessons learned for the future. Ann. N. Y. Acad. Sci. 1230, E19-E28. doi: 10.1111/j.1749-6632.2011.06215.x

UNFPA (2015). Implementing Comprehensive HIV and STI Programmes with Men Who Have Sex with Men. New York, NY: UNFPA.
Van Kesteren, N. M., Hospers, H. J., and Kok, G. (2007). Sexual risk behavior among HIV-positive men who have sex with men: a literature review. Patient Educ. Counsel. 65, 5-20. doi: 10.1016/j.pec.2006.09.003

Wagner, E. E., Miller, A. L., Greene, L. I., and Winiarski, M. G. (2004). Dialectical behavior therapy for substance abusers adapted for persons living with HIV/AIDS with substance use diagnoses and borderline personality disorder. Cogni. Behav. Pract. 11, 202-212. doi: 10.1016/s1077-7229(04)80031-2

WHO (2016). World Health Statistics 2016: Monitoring Health for the SDGs Sustainable Development Goals. Geneva: World Health Organization.

Willie, T. C., Overstreet, N. M., Peasant, C., Kershaw, T., Sikkema, K. J., and Hansen, N. B. (2016). Anxiety and depressive symptoms among people living with HIV and childhood sexual abuse: the role of shame and posttraumatic growth. AIDS Behav. 20, 1609-1620. doi: 10.1007/s10461-016-1298-9

Workowski, K. A., and Bolan, G. A. (2015). Sexually transmitted diseases treatment guidelines, 2015. MMWR Recomm. Rep. 64:1.

Conflict of Interest: RA was employed by Tactus Addiction Care, TH was employed by Scelta, and EF-V was employed by Youz.

The remaining authors declare that the research was conducted in the absence of any commercial or financial relationships that could be construed as a potential conflict of interest.

Copyright (C) 2020 Arends, van den Heuvel, Foeken-Verwoert, Grintjes, Keizer, Schene, van der Ven and Schellekens. This is an open-access article distributed under the terms of the Creative Commons Attribution License (CC BY). The use, distribution or reproduction in other forums is permitted, provided the original author(s) and the copyright owner(s) are credited and that the original publication in this journal is cited, in accordance with accepted academic practice. No use, distribution or reproduction is permitted which does not comply with these terms. 